\title{
Rioting and the politics of crisis
}

\begin{abstract}
This paper draws on selected explanatory accounts of rioting that occurred in England in 2011 for the purpose of illustrating the ways in which scholarly critiques frame quite different senses of what kind of 'crisis' the riots represented. On one side the riots are understood within a 'race and policing' frame placing in a line of continuity with events across time and space and in an on-going crisis of racial subjugation. In direct contrast, another side treats the riots as a crisis of post-politics, in which nihilism has replaced purposive political action. While different types of politics are centred in both approaches, they differ remarkably in relation to racism, with the latter treating race as epiphenomenal. These frames are instances of how critical scholarly understandings draw on events, and it is argued they miss potentially far reaching senses of 'crisis' that can be drawn out of some aspects of rioting.
\end{abstract}

Keywords: Racism, Policing, Protest, Scholarship, Framing, Critique 
At least since the influential and ground breaking work, Policing the Crisis (Hall et al 1978) matters of race, policing and crisis have been commonly in academic analyses. Rioting in the UK in the early 1980s deepened that nexus and for many years this has been a prism through which most riots or violent disorder has been understood (Benyon and Solomos 1987, Keith 1993, Smith 2013). By understood I am referring not to media commentary or to public debate, although it may also occur there, but to academic and scholarly coverage of events in the 1980s and since that has made racialisation a predominant approach to think through disorder and policing (Keith 1993, Holdaway 1996, Rowe 1998). The racial connection of the 2011 riots as primarily a matter of race and policing is due to its perceived echoes of events from the 1970s and 1980s when there were riots at the Notting Hill Carnival, and then in various inner cities, most notably Brixton in 1981 (Scarman 1981) and Brixton and Broadwater Farm in 1985 (Gifford 1986). In this vein, riots became an episodic but familiar part of the British landscape that made them an archetypal form of protest or mobilisation associated with race issues and racial minorities. Yet while the 2011 riots seem to speak to this history (Smith 2013), some interpretive frames can also erase race in curious ways, and the 2011 events are notable for the scholarly expression of a counter-view in which the riots were treated as marking a crisis of 'post-politics', and in which race and racism are given no or very limited significance.

In setting these out as two prominent 'ways of seeing' (Berger 1972) my purpose is threefold. First, to highlight how events are captured for particular ends in critical scholarship, either as a sign of continuing racism policing, or of the state of politics. Those ends are not illegitimate and they may even account for some aspects of riots, but their explanatory overreach is a problem. They lack specificity to times and places as they attempt to 'shoehorn' disparate events into somewhat singular frames, that itself signals the limits of these accounts. The sources included here appear in conventional academic publications such as books and journal articles, which also draw on official reports, blog posts and social media. In Hammersley's (2014) terms they are explanations, and go beyond description, because they infer or claim to know the causes of rioting. My purpose is not offer a counter-narrative of what 'really happened' in August 2011; timelines and a sense of how events unfolded are available in Morrell et al (2011) and the Riots, Communities and Victims Panel report (2012). Second, and recalling Rock (1981), while riots are often not amenable to any comprehensive account, their 'critical' framing does not allow for qualifiers or explanatory limits. This is about more than language and terminology. Rioting, as a set of messy and dispersed events in which the agency and identity of actors is disputed, lends itself to this argument but it is also evident in the ways 
that race is made significant. Even where race is centred it is done in a way that lends weight to some kinds of connections while obscuring others, as I show later. Third, I suggest that this argument may bear a wider claim about what is 'a' or 'the' crisis. What if instead of seeing the events as a 'race crisis' or a 'post political crisis' it was called something else, for instance, a 'legitimacy crisis'? The intended echo of Habermas (1975) here is instructive. Habermas' concern with tendencies of capitalist and liberal welfare states perhaps matters less here than his more general invocation of a legitimation crisis as a decline in or loss of confidence in the administrative and leadership capabilities. Viewed in this light, riots and protests may be thought of small instances that reflect failures of policing and of politics, though in a different manner to the accounts of the events to be discussed.

Frames and framing are commonly applied in media studies (Fairhurst and Sarr 1996) and employed in an analogous way, as in Butler (2009) who uses it to suggest how a frame is a device to identify what is being brought to attention, or into the centre of the analysis or explanation. It is this sense of framing I am relying on here, but for the purpose of drawing attention to partialities in scholarly analysis. While mainstream media accounts provide a 'preferred reading' of such events, my contention is that scholarly appraisals are also forms of preferred reading, even when they are cast as oppositional readings against an orthodoxy. They have a built-in diagnostic that instead of challenging 'mainstream' views, re-tread wellestablished tropes and perspectives that riots provide a pretext or a headline for. Hence, this paper is not a 'reading of the riots' that occurred in 2011, but rather a characterisation of two prominent ways those events were framed. It does not try to cover every reading or analysis of the riots, but it is not based on a merely random selection either. The sources covered are selected for the purpose of the position being presented but they are also among the main or key examples of the two types to be discussed. These different 'ways of seeing', or framing, interpreting, capturing and explaining riots is the primary focus of this paper. Although there are stark differences between them they are not intended to be seen as simple opposites. In Badiou (2012) for instance, there are traces of both in his portrayal of riots, protests, urban social movements and the 'Arab spring' as connected to police/state racism, as well as to apolitical consumerist looting. Similarly, Clover's (2016) reading also contains elements of both.

So while the paper does discuss the 2011 riots, it draws on them for a specific purpose. I provide a brief overview for some context only. Like violent disorders in the USA in 2014-16 (Camp and Heatherton 2016), the 2011 riots are commonly said to have started from the fatal shooting 
[hence calling them 'trigger' events is hardly appropriate in the circumstances] by Metropolitan police officers of Mark Duggan, a young man of mixed race origins in August 2011, in Tottenham, north London. While the police claimed Duggan had a gun and an illegal firearm was found, it was some distance from the car he was in. Community anger over the shooting led to a protest at the local police station which tipped over into widespread disorder and some looting in the area. Violent disorder continued into the next day and subsequently there were riots, including looting, across various parts of north, east, south and west London. Riots of varying scale and intensity also occurred in other cities such as Birmingham, Bristol, Liverpool, and Nottingham on the following days (Riots, Communities and Victims Panel 2012, Morell et al 2011). This short account signals that while events began from the police shooting of a black/mixed race male in an ethnically and racially mixed area of London, rioting also occurred in other English towns and cities that have less notable African-Caribbean populations, or have been significantly gentrified in recent decades, such as Battersea in London and Salford in Manchester. Thus, the August 2011 riots 'were different phenomena in different cities and even in different parts of the same city’ (Home Affairs Committee 2011, p.3).

\section{'Only connect': a crisis of race and policing, and beyond}

Probably the most common and recognisable scholarly trope employed in understanding the riots is by 'connecting' them to other times and places, and this established a 'causative chain' between here/now and then/there. Connecting can also work by way of contrast, which I mention at the end of this section. In the main, connecting occurs through contextualisation or comparison, and it is generally done in a critical vein to imply or to assert continuity between past and present, or between different places, commonly ones with established and recent histories of race conflict. Linking or connecting the events of 2011 across time and space to other 'similar' times and places is illuminating in terms of how racial connections are imagined and made, across time and space, and consequentially to the same or similar kinds of underlying causes, usually racism and/or racially discriminatory policing, or in extended forms, to social and economic inequality. It can be seen just in the titles of two short articles: Jefferson's (2011) 'Policing the Riots: From Bristol and Brixton to Tottenham, via Toxteth, Handsworth etc'; and Tyler and Lloyd's (2014) 'From Tottenham to Baltimore', which references the riots in the US city following the funeral of an African-American man, Freddie Gray, who had died from spinal injuries a week after being taken into custody by the police. These titles exemplify the 'from X to Y' type connection made between the 2011 riots and other places and other times; 
indeed the connection is made temporally as well as in spatial terms, as Jefferson (2011) invokes places that were at the centre of 'race' riots in the 1980s.

In each case, whether within Britain or across the Atlantic, the common thread is racism, and policing and social justice/inequality. Jefferson connects 2011 to places and a time - the context of the 1980s riots - in predominantly or recognisably, black, or African-Caribbean population areas, some of which were designated as 'symbolic locations' for policing where policecommunity conflict had become entrenched and routine (Keith 1993). Tyler and Lloyd make a more contemporaneous but transatlantic connection between racially unjust policing in England and in the USA, that, for Kelley and Tuck (2015), is 'the other special relationship' between the two nations. In these accounts the 'spark' that can light a fire and move from low level to violent disorder is embedded in the everyday contacts between the police and back people. In spite of changes to police procedure and policy around key issues such as stop and search in the decades since the 1980s (Hall, Grieve and Savage 2009) it remains a key aggravating feature of everyday interactions. Social and economic inequality provides the context that shapes these encounters and experiences. 'Connecting' brings out such ways of understanding the 2011 riots as a moment of crisis, where a crisis is a rupture in time and space, but also one that has deep roots and histories that connect the antagonistic relationship of race and policing in urban locations. Thus, there is both a continuous crisis, as well as episodic crises that take an expressive form such as rioting. Empirical evidence of statistical disproportionality and complaints about police harassment, including the use of the 'sus' law historically, and stop and search (or stop and frisk in the USA) underscores plays a key part in this argument about 'endless pressure', where black people, often male and young, are simultaneously over-policed as 'criminals' but under-protected (McGhee 2005) as victims with regard to gun and knife crime, particularly in large cities like London.

While 'from Tottenham to Baltimore' represents the ' $\mathrm{X}$ to $\mathrm{Y}$ ' style of connecting places, a notable feature of 2011 is not the link from X to Y, but rather of $\mathrm{X}$ to $\mathrm{X}$, 'from Tottenham to Tottenham' as it were. This form of this connection is revealing for the ways claims are framed, as well what is obscured or overlooked. The ' $\mathrm{X}$ to $\mathrm{X}$ ' connection is to violent disorders in broadly the same area, at Broadwater Farm in 1985 (Gifford 1986, Keith 1993). The close colocation of these two events, even spread over 36 years, speaks powerfully to a sense of ongoing racialised inequality, as well as unresolved problems with policing. In both 2011 and in 1985 the events are connected to the deaths of black people in contact with the police, itself a matter of concern over more than five decades (Athwal and Bourne 2015). In this light, the riots in 
Tottenham in 2011 were not 'meaningless' violence but an event haunted by the riot of 1985 . The connection between them was commonly reported in the media, by commentators and other analysts. Tottenham was referred to as a place with a history of riot, a history made more charged because the 1985 riot involved the death of a police officer PC Keith Blakelock, a point that was also prominent in a verbatim play on the riots (Slovo 2011).

While racism and policing is the core of the frame, the analysis within it can be stretched to invoke a broader political-economic crisis. A near contemporaneous example of this is found in internet sites such as Ceasefire magazine and in Adam Elliot Cooper's blogposts that begin with policing and then expand to other issues, that makes the riots understandable as 'redefining the political' (Cooper 2011a). In September 2011 his starting point is comments made by rioters of the police as a lawless, 'institutionalised gang' in inner city areas, a term itself invoking the notion of the police as an 'army of occupation' in black areas in the late 1970s (Gilroy 1987, Keith 1993). He views the police in blunt terms as part of the repressive state apparatus, being 'used by the state to control and repress, not maintain stability or uphold justice', on behalf of 'a state machine which racialises, impoverishes and dehumanises' black communities' (Cooper 2011a). Later, drawing from the voices of people on the street he notes that 'young people affected by the uprising....offer their own analysis of the political... on unemployment, the cuts to $\mathrm{EMA}^{\mathrm{i}}$ and youth services, police powers, media and political corruption, poverty and racism.' This extension beyond policing is an indication of how riots come to be linked to poverty, inequality and political-economic issues. While in the second frame to be discussed looting is seen as failed consumerism, for Cooper (2011b) it is purposive in a way that implicitly draws on moral economy (Thompson 1967). Thus, the stores targeted, such as JD Sports and Footlocker, are seen as both purveyors of desirable brands and consumer capitalism, but also as a form of (symbolic) violence toward poor people in deprived areas who find that the goods are well beyond their reach (Millington 2016). On other sites and in social media there was a suggestion that these shops were targeted because of their exploitative approach in paying minimum wages and refusing to employ local people. Widening the frame from rioting to political diagnosis is seen in other sources also. Tyler (2013), for instance, links it to the abjection and stigmatisation of the poor in the UK under neoliberal economic policies; others emphasise widening social inequality as a key factor linking and underlying rioting in history (Grover 2011) and casino finance capitalism (Monaghan and O’Flynn 2011).

The analyses in the connecting frame exemplify narrower and wider claims, where the latter draws in critiques of capitalism, the financial crisis and economic inequalities, while the former 
looks more to factors such as policing and community conflict. In terms of level these diagnoses can be pitched at local, national and/or global issues. Locality perspectives usually highlight local police/community relations in specific places, often ones with racialised associations, as in Jefferson (2011), though Cooper (2011a, b) goes beyond that. National views draw attention to the restructuring of the welfare state, increasing poverty and the politics of austerity, as in Tyler (2013), while global analyses centre casino capitalism, the banking crisis, and neoliberalism. Tyler's (2013) approach also aims to suggest the intersections between these levels analytically. However, all of these contain the common problem of structuralist analysis: how to link the 'objective' social and economic conditions with the 'subjective' motives, understanding and actions of individuals and groups. 'Political' intentionality and readings may apply to some people and events in some places, but is the explanatory reach intended to encompass all events or just particular ones? Even when applied to specific places, such as Tottenham, which can be closely contextualised in terms of local histones of policing, experience of inequality and a widening gap between rich and poor, is the explanation pitched at the level of the riot as a whole, or can it include the diversity of actions and actors that took part in that? The messiness of riots, even in one location, do not lend themselves to any neatly bounded explanations.

Resolutions to that problem include viewing the actions of rioters as 'proto-politics' (Millington 2016), or by invoking a sense of latency in their consciousness or experience via the concept of habitus, as Akram (2014) does. Taking politics to refer to the contestation of the uneven distribution of power and resources, Akram identifies the key problem as the gap between the sense of grievance expressed by rioters - and their general demographic profile as people from socially deprived backgrounds - and the lack of an explicit political strategy or even any great sense of engagement with politics. Akram (2014, p.383) argues that 'grievances and motivations are stored until they are triggered in the rioter's habitus. This means that, whilst individuals may have concerns about issues, they may not feel able to do anything about them, or there are few channels to do so. However, the riot, or its triggering events, represents an opportunity for stored grievances to be expressed, because the riot represents a rupture in the habitus'. Like others (eg Badiou 2012), this places great weight on a 'triggering' event, without developing a model of how that is communicated, understood, deployed and invoked in events. It draws on the 'flashpoint' models of disorder (Waddington 1992), but displays the same key shortcoming: why or how is it that many, or even daily, possible flashpoints do not lead to riots. Moreover, its focus on the spectacular and expressive forms of violent disorder prioritises that 
over ongoing and everyday low level social disorder, or 'slow rioting' (Waddington et al 2011). Hence, while connecting by comparison in a diagnostic vein is not implausible, it can lack specificity to times and places, as well as how far it applied to individuals and groups. It requires a better link or connection between everyday 'endless pressure' - daily and routinized experience, both current and remembered, of police and racial discrimination - and large scale disorders. While an explanation or a frame cannot cover everything, its partialities - the selective nature of what gets connected to what - as well as its focus ought to be reason to pause before asserting connections with any deep seated confidence

In terms of crisis politics the connecting frame proffers a critique - of policing, austerity politics and/or neo-liberalism - but that overlooks, I argue, a potentially more modest but maybe also more powerful critique. To illustrate this I need to spell out a connection that is not commonly evident in writings on the 2011 riots. The ' $X$ to $X$ ' connection of Tottenham in 2011 is to Broadwater Farm in 1985, as already stated. However, a different connection between 2011 and 1985 provides another narrative of crisis. The protests that followed the Duggan killing eerily echoed the events surrounding the police shooting of a black woman, Cherry Groce, at her home in Brixton in 1985, in a raid where the police were targeting (details of this event appear in various sources on the 1980s riots cited). That shooting also led to a protest around the local police station and, eventually, disorder. The connection between these two events can be used to propose that the start of the 2011 riots is less to do with everyday policing but instead the rarer but highly consequential use of firearms. In both cases, it is possible that police action in the wake of the shootings could have prevented or contained rioting. The common failure in the two situations was that of the police to draw on and implement their family liaison procedures that required them to communicate with and support the Duggan/Groce families. The inadequate response of the Metropolitan Police in the immediate aftermath of Duggan's death contributed directly to the mood of the organized protest at Tottenham police station on 6th August 2011. Poor or non-existent communication with the family of Mrs Groce was undoubtedly a factor in Brixton in 1985. In other words, in terms of policy, this speaks to an institutional failure. It could be called a crisis in light of the fact that by the time of Tottenham in 2011, it is hardly something the police can claim to be surprised about since, in between those decades, the most high profile issue of race and policing was their poor handling of and dealings with the family of Stephen Lawrence after he was stabbed in 1993; those shortcomings were central to Macpherson's (1999) path-breaking formal finding of the police as being institutionally racist. 
After Macpherson, family liaison techniques became a focus for policy improvement through sustained critical incident or 'crisis management' training (Hall et al 2009). Despite that, around a key and long standing concern - race relations in an inner city location such as Tottenham - ineffectual family liaison and critical incident management signal a sense of policy and institutional failure, or even crisis. Elaborating this viewpoint still puts events squarely within a race and policing frame, but as an alternative way of connecting events and issues it produces a significantly different analysis of 'crisis'. It offers an institutional prescription that is lacking in most scholarly accounts, though the issue of family liaison is clearly identified as a community concern and a police mistake in the Home Affairs Committee (2011) report. Extending it as I have done it to suggest that the crisis that Tottenham 2011 represents is or could be about legitimacy in the Habermasian sense that institutions of state cease to function effectively. In terms of the argument of this paper the other crucial point is that a largely overlooked and 'minor' policy theme opens the way to a far reaching critique.

Other connections not made or underplayed are also revealing for the way the 'race narrative' of the 2011 riots is constructed. While in terms of race there are aspects of 2011 that can plausibly linked to 1981 and 1985, other events in between those decades are remarkably muted. For instance, the 2011 riots are generally not read in relation to riots in 2001 in northern English towns, which were mainly associated with people of South Asian descended populations; nor to 'white' riots in places such as the Blackbird Leys estate in Oxford in 1991. In other words, connecting to the 1980s emphasises some places and neglects others, setting up a preferred narrative that forms the race and policing connection. Another consequence of stressing place continuity is that considerable demographic shifts and changes in a locality such as Tottenham. The arrival and settlement of newer and different migrant communities makes the area superdiverse to an extent, as reflected in the make-up of both rioters and victims, including the local Turkish/Kurdish shopkeepers who used self-defence campaigns to protect their property (Lewis et al 2013). In areas such as Gloucester, Enfield, and Ealing, which also witnessed rioting and all have very mixed populations, also call into question a strong race narrative of the 2011 riots. Drawing attention to these absences, oversights and different geographies is not to undermine 'connecting' but to point to its selectivity. In other cases, however, connecting is undercut through a method of contrasting the 2011 riots with other disorders. For some, earlier riots and in different places, disorder, even involving violence, was understandable as a political protest, as in the 1960s Civil Rights demonstrations in the USA. 
By contrast, the 2011 events are said to lack any substantial cause; they are a form of misguided or defective rage, and this is the nub of the post-political frame.

\section{'Shopping for free': the crisis of post-politics}

The most obvious contrast with the preceding frame, which aims to identify some kind of political intentionality in rioting and read that in light of histories of racist over-policing and against conditions of inequality, would be one in which any political intentionality is denied. Such responses are usually in a 'knee jerk' law and order reflex such as the description of them as 'pure thuggery' by the Home Secretary, Theresa May, or in the comment of the Mayor of London, Boris Johnson, "Its time we stopped hearing all this (you know) nonsense about how there are deep sociological justifications for wanton criminality and destruction of peoples' property". ii Along with the similar tone taken in the first reaction of the Prime Minster, such statements are widely quoted (some of which can be found in Hammersley 2014, and Kelley and Tuck 2015, as well as in other sources cited) in critical approaches as a sign of how outof-touch and predictable such responses are, not least as they repeat similar words made in regard to rioting in the 1980s (Benyon and Solomos 1987, Rowe 1998) and before that to 'race and crime' generally (Hall et al 1978). While they are familiar it is not the case that they always fit into a simple narrative. Even in August 2011 when the riots occurred the Prime Minister and Leader of the Opposition both condemned violence but also suggested there were complex causes behind the riots, and such change over time is commonly overlooked (Hammersley 2014), Moreover, while 'right wing' reactions do blame feckless families and welfaredependency they can also be more nuanced than that. For instance, Iain Duncan Smith, the Secretary of State for social welfare, a politician commonly regarded as being on the 'hard right' of the Conservative Party, wrote in 2011 that:

while we have to be tough on the perpetrators and on the gangs, we also have to ask ourselves what lies behind this. We cannot simply arrest our way out of these riots... The riots have provided a moment of clarity for all of us, a reminder that a strong economy requires a strong social settlement, with stable families ready to play a productive role in their own communities. The challenge of our generation is to reforge our commitment to reform society so that we can restore aspiration and hope to communities that have been left behind. ${ }^{\text {iii }}$

The appeal to 'stable families' and restoring 'aspiration' is quite different from the political and policy prescriptions that come out of the preceding frame, but it is the not the same as 
denying any politics in riotous disorder. In Duncan Smith's view of 'communities... left behind' there is a suggestion that governments bear some responsibility for that, as well as by markets or their own actions. The 'integration' strategy (Casey 2016) that flows from it is a mixture of punitive as well as welfare measures that does responsiblize people in poverty (Tyler 2013) but it is not merely about more 'law and order', not least in a period since 2010 where a Conservative-led government had been reducing police resources.

Demands for more policing, tougher sentences and punishment is a common refrain in rioting of all kinds and usually linked to right wing and authoritarian politicians and commentators. Such enforcement/police led perspectives appear to contrast with more 'social democratic' responses that stress 'repair', in the form of community building, better education, housing and welfare and even, at times, anti-racism. Yet Duncan Smith's words cut across that to an extent. While there can be quite large differences of emphasis and inflexion, the responses of left and right do overlap. Lord Scarman’s (1981) report into Brixton disorders, for instance, can be read as a liberal document that recommended better community facilities and bridge building between the police and black communities, as well as heralding a decade of increasing 'tooling up' by the police in preparation for more violent disorder. In spite of the many critical objections to Scarman at the time, in Hall's (1982) incisive reading the report it did not conform to any simple liberal/reactionary divide. He saw that it contained elements of both and also marked an attempt at a new kind of settlement. Hence there is some continuity between left and right views as well as less predictability about what is 'left' and what is 'right' in readings of rioting. Three decades on, responses to the 2011 riots also demonstrate that. A denial of politics in the 2011 riots appears in the report of the Labour-led Parliamentary Home Affairs Committee (2011, p.31), for instance. It observed that though there could have 'been an element of disengagement' among some of those involved in the riots, but it adds that, 'unlike some events in the past, including the riots in the 1980s, there does not seem to be any clear narrative, nor a clear element of protest or clear political objectives'. This does rather beg the question of what 'clear' means in relation to 2011. Contextualised as a matter originating from a black death in contact with the police, there are clear links from 1985 to 2011. The spread of riots to many other places may lack the 'clear narrative' the Committee refers to, but to wilfully fail to recognise race as a starting point seems to be a determinedly narrow and self-limiting outlook. It too display the contrast method where the 2011 events are cast unfavourably in relation to previous events. Politics 'then' is invoked to rule out politics 'now'; thus it is not the absence of politics per se but a matter of how it is raised. 
If the 1980s was the decade of monetarism, by the twenty first century the master category is neoliberalism, particularly in light of the banking and financial crisis from 2008 (Harvey 2012). This context produces two almost diametrically opposite points of view. In one rioting is a kind of, maybe nascent, political activity against poverty and inequality, as in the preceding frame; while in another perspective, the 2011 riots are seen as marking an absence of politics, or a 'post-political' reaction of failed rage by defective consumers. It is typified by Bauman's (2011) widely quoted remarks about the events: 'These are not hunger or bread riots. These are riots of defective and disqualified consumers... We are all consumers now, consumers first and foremost, consumers by right and by duty'. Building on this, Zizek (2011) commented that the riots were, more than anything else, 'a manifestation of a consumerist desire violently enacted when unable to realise itself in the 'proper' way - by shopping.' For Zizek, the events 'contain a moment of genuine protest' but it 'is impotent rage and despair masked as a display of force'. Thus in Zizek as well as in Bauman there is a sense that there are 'objective' economic conditions that require political protests against capitalism, but the form the riots took - directionless violent disorder whose main achievement was to acquire desirable consumer goods through looting - is not an expression of that.

The crisis of post-politics is a time or an era where alternative political imaginaries, as well as faith in the capacity of the state to effect progressive change, have been ruled out of court under neo-liberal domination; in this context, the legitimation crisis is the failure of left political leadership. The most developed exposition of the 'shopping for free' perspective is in Treadwell et al (2013) and Winlow et al (2015). Taking their cue from the view that the dominance of neoliberal and managerialist logics have undermined leftist political strategy against capitalism their analysis follows Zizek in seeing rioters as post-political subjects incapable of collective action and driven by individualism and consumerism, or what they describe as the 'shallow pleasures and distractions of consumer culture'. As with the Home Affairs Committee (2011) it is significant that is not disorder per se that underlies their objection as view earlier riots and protests as expressions of political grievances: 'In previous eras, the marginalized subject was... active in.... political collectives... [and] able to find collective support... to articulate [its] rage onto the real socio-economic, ethical and political causes of dissatisfaction'. However, unlike what they see as the solidaristic politics in those, now 'it seems almost impossible for a potential collective of marginalized subjects to construct a universal political narrative that makes causal and contextual sense of their own shared suffering and offers a feasible solution to it’ (Treadwell et al 2013, pp.1-2). 
Once again, there are conditions that call for political reaction, so it is the disorganised form of that in rioting that these authors see symptomatic of post-politics. This covers misguided street politics, a lack of alternative ideologies to neoliberal capitalism, and a failure to think of solidarity in class terms, rather than what they call 'protests...structured in relation to the needs and wants of specific micro-communities' (Winlow et al 2015: 203). This speaks to their rejection of cultural politics and the politics of difference, in which race is a form of 'identity politics', promoted by some leftists In this regard the riot becomes a metaphor for a type of non- or futile politics:

In many cases, no progressive politics exists within the frame of the riot, and there is no seductive image of an ideological alternative for people to rally around. Instead, the riot is driven forward by an incoherent rabble of pissed-off individuals incapable of joining together to form a genuine political community. In the context of the postpolitical present, the riot is more a depressive acting out of deep, objectless frustration and anger than a concerted proto-political intervention demanding change. In most cases, the only vague hope we have been able to identify among contemporary rioters is the desire to be re-included into the very socio-economic system that excluded them in the first place (Winlow et al 2015: 203).

Their argument is based on some empirical work with rioters, though other empirical research questions their analysis. Newburn et al (2015) observe that looting is a usual rather than an exceptional feature of riots. The stress on it by Treadwell et al (2013), Winlow et al (2015) and Zizek (2011) enables them to draw on it for the purpose of an argument about the nature of disaffected consumer capitalism among rioters whose purpose is just to be 'included' as capitalist subjects. Yet the more comprehensive LSE/Guardian study which interviewed around 270 people in the first phase (Treadwell et al interviewed 30 people, by comparison), Newburn et al show that rioters do express a mixture of motives, including dissatisfaction with politics and the police. Reducing that to, or focussing only on the desire to acquire free goods is to miss such views, while using Thompson's (1967) 'moral economy', Newburn et al (2015) also suggest that the targets of looting are not random and violence can be understood as directed in some cases.

While Winlow et al (2015) call for alternative political imaginaries, their 'pessimistic' view of any political solidarities in rioting is symptomatic of a kind of 'narrative of decline'. Nostalgia is one a form of cultural pessimism that Bennett (2001) identified as a trope in which a nation 
or culture, or in this case, political agency, is regarded as in irreversible decline. Its invocation may say more about the psychic disposition of those who reach for or appeal to 'genuine political community', 'universalism' and a seeming harking back to class politics, without difference. Treadwell et al (2013) acknowledge that riots are messy and complex, but their refusal to see in at least some parts of them elements of solidarity and collective action is to adopt a blinkered view of what counts as politics. New social movements, such as Occupy, also fail their test, though, like Harvey (2012), they do see elements of hope in some political alternatives such as the Syriza movement in Greece. For Harvey also, the 2011 riots are a poor relation to 'real' politics because they bear no relation to 'various glimmers of hope and light around the world' such as the movements in Spain and Greece, Latin America. Unlike the London rioters, Harvey maintains that the latter movements can 'see through the vast scam that a predatory and feral global capitalism has unleashed upon the world' (p.157). Thus, these writers bemoan the decomposition of class politics and look to it as a basis for anti-capitalist movements. In doing so they adopt a rather race blind view of such politics and the intersections of race and class (Virdee 2014). While I have proposed that the 'race and policing' frame makes too much of race, in a way that overlooks rioting in places and at times that do not fit that narrative, in post-politics there is a stark reversal where race and racism are either absent or epiphenomenal. In spite of the messiness of riots, their varying locations and the multi-racial composition of rioters, there is evidence that encounters with the police are an aggravating factor, as to an extent is inequality among and within definable demographic groups (Lewis et al 2013, Newburn et al 2015). It is arguable if the actions are directed in the ways that some see (Akram 2014, Millington 2016) but to treat them as 'race blind' and as directionless consumerism is, perhaps bizarrely for a high-level perspective, to miss the bigger picture by focussing on some details.

\section{Conclusion}

In selecting and assessing two ways the 2011 riots have been framed the purpose of this paper was to treat them as analyses that centre or decentre race, provide contrasting senses of what the politics of rioting amount to, and convey varying notions of what crisis the events are viewed as a symptom of. Although elements of both forms of explanation can be found in the post-hoc accounts of rioters, these approaches share the common problem of any unqualified treatment of what goes on in riots, of accounting for variation across time and place, as well as the diversity of individuals and groups; this makes both more tenuous as explanations. The 'race and policing' frame can make some credible links between past and present and 'here' 
and 'there'; however, the associations made reveal a preferred narrative that supports some sense of continuity but is less adept at addressing social, policy and demographic changes over time. The racial signification of rioting in the 1980s is powerful, but then as in 2011 the heterogeneous nature of cities and issues around over-policing and social injustice extend beyond race. Race is clearly necessary in understanding some of what occurred in 2011 but it is not sufficient; the same also applies to the police/policing. The 'post- political' frame highlights nihilism and looting in the riots but it does so at the expense of downplaying the latter as routine, not exceptional. More importantly, it does not give due weight to the grievances about policing and sense of injustice that rioters did express (Lewis et al 2013). It wilfully neglects the politics of race and racism that has been prominent since the 1980s in order to buttress a view of failures in organised politics, in which 'identity politics' is itself seen as a cause.

Reflecting briefly on the USA, there is a strong case to view recent [2014-16] events there as a race crisis if race is constitutive of and an inescapable feature of the events. The centrality of racialised experience and subjugation is undeniable because of the local and national histories of racism and racially unjust policing, which has formed the basis of the now well-known and transnational campaign Black Lives Matter. ${ }^{\text {iv }}$ That race is at the core is evident as even those who want to deny that racism is the issue lean on racialised explanations, such as the absence of father figures or poor parenting in black communities. While there are traces of such a narrative or analysis to be made in Britain, race is crucial to some times and places, but not necessarily to all locations that witnessed rioting.

While rioting as example lends itself to a case against totalising approaches, my wider argument is about styles of critical scholarly analysis that fit such events into a preferred framework or narrative, and as signs of some type of crisis. Readings of all riotous assembly could be criticised in this way but my point is more specific. The two frames provide varying definitions of the issue or problem; they are too broad in their sweep but also too narrow, in stressing some things and ignoring or overlooking others. If read through a 'legitimacy crisis' perspective, the connecting frame casts light on the continuing problems of policing, but with little sense that the issues identified, such as stop and search, have been widely researched and subjected to policy changes; what comes after or out of all that remains an unanswered question. By pointing an alternative connection - between Brixton 1985 and Tottenham 2011 - I have indicated how a/the crisis could be framed differently, as an institutional problem. This more modest analysis provides, I argue, a far reaching critique of police policy. Meanwhile in 
post-politics, the failures of legitimacy lie with political leaders and organisations that means rioters are directionless and selfish actors. Whether, some years on, the social movements criticised in this perspective, as well as the 'glimmers' of hope they perceive, do or do not represent alternatives to capitalism is a question that goes well beyond rioting. Public disorder such as the 2011 riots are treated largely a symbol or a metaphor for a wider argument that is unconvincing in terms of specifics, such as 'shopping for free', but is in general un-anchored from the place(s) or context(s) of rioting. To make sense of events as a 'crisis', whether continuous or periodic, calls for an analytical gaze that can resist the temptations of grand narrative claims as a form of critique, and instead be alert to what is and is not continuous over time and how, and if, places can be linked. 


\section{REFERENCES}

AKRAM, S, (2014), Recognizing the 2011 United Kingdom riots as political protest: A theoretical framework based on agency, habitus and the preconscious, BRIT. J. CRIMINOL. 54, 375-392

ATHWAL, H AND BOURNE, J (eds) (2015) Dying for justice, London: Institute of Race Relations

BAUMAN, Z (2011) 'The London Riots - On Consumerism coming Home to Roost' Social Europe Journal, 9 August

BADIOU, A (2012) The Rebirth of History: Times of Riots and Uprisings, London: Verso BENNETT, O (2001) Cultural Pessimism: Narratives of Decline in the Postmodern World Edinburgh: Edinburgh University Press

BENYON, J AND SOLOMOS, J (eds) (1987) The Roots of Urban Unrest, Leicester: Scarman Centre

BERGER, J (1972) Ways of seeing, London: Penguin

BUTLER, J (2009) Frames of war: when if life grievable? London: Verso

CAMP, J AND HEATHERTON, C (eds) (2016) Policing the Planet: Why the Policing Crisis Led to Black Lives Matter, London: Verso

CASEY, L (2016) A review into opportunity and integration; available at: https://www.gov.uk/government/uploads/system/uploads/attachment_data/file/575973/The_C asey_Review_Report.pdf

CLOVER, J (2016) Riot. Strike. Riot: The New Era of Uprisings, London: Verso

ELLIOT COOPER, A (2011a) 'Redefining the political', at: https://ceasefiremagazine.co.uk/the-anti-imperialist-12-1/11 Sept 2011 The UK riots: redefining the political

ELLIOT COOPER, A (2011b) 'Advertising as a form of violence', at: https://ceasefiremagazine.co.uk/anti-imperialist-12-2/18 Sept 2011.

FAIRHURST, G. \& SARR, R. (1996) The art of Framing. San Francisco: Jossey-Bass 
GIFFORD, T (1986) The Broadwater Farm inquiry: report of the independent inquiry into disturbances of October 1985 at the Broadwater Farm Estate, Tottenham, London: Karia Press GROVER, C, (2011) Social Protest in 2011: Material and Cultural Aspects of Economic Inequalities, Sociological Research Online, 16 (4)

HABERMAS, J (1975). Legitimation Crisis. Boston, MA: Beacon Press

HALL, N., GRIEVE, J. AND SAVAGE, S. (eds.) (2009) Policing and Legacy of Lawrence, Devon: Willan.

HALL, S (1980) 'Encoding/decoding'. In Centre for Contemporary Cultural Studies (Ed.) Culture, Media, Language. London: Hutchinson

HALL, S. (1982) 'The Lessons of Lord Scarman', Critical Social Policy, no. 2, pp. 66- 72.

HALL, S et al (1979) Policing the Crisis, London: Macmillan

HAMMERSLEY, M (2014) The Limits of Social Science, London: SAGE

HARVEY, D. (2012) Rebel Cities: From the Right to the City to the Urban Revolution. London: Verso

HOLDAWAY, S (1996) The Racialization of British Policing London: Macmillan

HOME AFFAIRS COMMITTEE (2011) Policing Large Scale Disorder: Lessons from the disturbances of August 2011, London: The Stationery Office

KELLEY, R. AND TUCK, S. (Eds.) (2015) The Other Special Relationship: Race, Rights, and Riots in Britain and the United States, New York: Palgrave

KETTLE, M. AND HODGES, L (1982) Uprising! The police, the people and the riots in Britain’s cities Macmillan: London.

MCGHEE, D (2005) Intolerant Britain? hate, citizenship and difference, Maidenhead: Open University Press

MACPHERSON, W. (1999) The Stephen Lawrence Inquiry, London: The Stationery Office MILLINGTON, G (2016) “I found the truth in Foot Locker”: London 2011, Urban Culture, and the Post-Political City, Antipode, vol 48 (3), pp.705-723 
MONAGHAN, L AND O’FLYNN, M, (2011) More Than Anarchy in the UK: 'Social Unrest' and its Resurgence in the Madoffized Society, Sociological Research Online, 17 (1) 9

MORRELL, G, SCOTT, D, MCNEISH D AND WEBSTER, S (2011) The August riots in England Understanding the involvement of young people, London: NatCen

NEWBURN, T, COOPER, K, DEACON, R AND DISKI, R, (2015) Shopping for free? looting, consumerism and the 2011 riots, BRIT. J. CRIMINOL. 55, 987-1004

RIOTS COMMUNITIES AND VICTIMS PANEL (2012) After the riots, available at: http://webarchive.nationalarchives.gov.uk/20121003195935/http://riotspanel.independent.gov .uk/wp-content/uploads/2012/03/Riots-Panel-Final-Report1.pdf

ROWE, M (1998) The Racialization of Disorder in Twentieth Century Britain Aldershot: Ashgate

SCARMAN, L (1981) The Brixton Disorders 10-12 April 1981. London: HMSO.

SLOVO G (2011) The Riots, London: Oberon

SMITH, E (2013) Once as History, Twice as Farce? The Spectre of the Summer of '81 in Discourses on the August 2011 Riots, Journal for Cultural Research Vol. 17, 2: pp. 124-143

THOMPSON, E. P. (1971) 'The Moral Economy of the English Crowd in the Eighteenth Century’, Past and Present, 50: 76-136

TREADWELL, J., BRIGGS, D., WINLOW, S., \& HALL, S., (2013) 'Shopocalypse Now: Consumer Culture and the English Riots of 2011', British Journal of Criminology, 53(1), pp117

TYLER, I. (2013) The Riots of the Underclass? Stigmatisation, Mediation and the Government of Poverty and Disadvantage in Neoliberal Britain, Sociological Research Online, 18 (4)

TYLER, I AND LLOYD, J (2015) From Tottenham to Baltimore, policing crisis starts race to the bottom for justice', The Conversation 1 May 2015. At: http://theconversation.com/fromtottenham-to-baltimore-policing-crisis-starts-race-to-the-bottom-for-justice-40914

VIRDEE, S (2014) Racism, class and the racialized outsider, Basingstoke: Palgrave Macmillan WADDINGTON, D. (1992) Contemporary Issues in Public Disorder, London: Routledge 
WADDINGTON, D, JOBARD, F AND KING M (eds) (2011) Rioting in the UK and France, Abingdon: Taylor and Francis

WINLOW, S, HALL, S, TREADWELL, J AND BRIGGS, D, (2015) Riots and Political Protest: Notes from the Post-Political Present, Abingdon: Routledge

ŽIŽEK, S, (2011) “Shoplifters of the World Unite”, London Review of Books, 19 August

\section{Notes}

\footnotetext{
'EMA refers to the Education Maintenance Allowance that was withdrawn by the $2010-15$ UK coalition government.

ii These quotes are from this blogpost: http://sociologyandthecuts.wordpress.com/?s=keith).

iii In The Times, 15th September, 2011

iv See: http://blacklivesmatter.com/
} 